Research paper

\title{
Schistosoma antigens downregulate CXCL9 production by PBMC of HTLV-1-infected individuals
}

\author{
Luciane Mota Lima ${ }^{\mathrm{a}, *}$, Luciana Santos Cardoso ${ }^{\mathrm{a}, \mathrm{b}, \mathrm{g}}$, Silvane Braga Santos ${ }^{\mathrm{a}}$, \\ Ricardo Riccio Oliveira ${ }^{\mathrm{a}, \mathrm{c}}$, Sérgio Costa Oliveira ${ }^{\mathrm{d}}$, Alfredo Miranda Góes ${ }^{\mathrm{d}}$, Alex Loukas ${ }^{\mathrm{e}}$, \\ Maria Ilma Araujo a,f,g \\ a Serviço de Imunologia, Hospital Universitário Professor Edgard Santos, Brazil \\ b Departamento de Análises Clínicas e Toxicológicas, Faculdade de Farmácia, Universidade Federal da Bahia, Salvador, Bahia, Brazil \\ ${ }^{c}$ Centro de Pesquisa Gonçalo Muniz. Fundação Oswaldo Cruz (FIOCRUZ), Salvador, Brazil \\ d Instituto de Ciências Biológicas, Departamento de Bioquímica e Imunologia, Universidade Federal de Minas Gerais, Brazil \\ e Australian Institute of Tropical Health and Medicine, James Cook University, Queensland, Australia \\ ${ }^{\mathrm{f}}$ Escola Baiana de Medicina e Saúde Pública, Salvador, Bahia, Brazil \\ g Instituto Nacional de Ciência e Tecnologia em Doenças Tropicais - INCT-DT(CNPq/MCT), Brazil
}

\section{A R T I C L E I N F O}

Article history:

Received 29 February 2016

Received in revised form 8 December 2016

Accepted 23 December 2016

Available online 28 December 2016

\section{Keywords:}

HTLV-1

Schistosoma proteins

CXCL9

CXCL10

\begin{abstract}
A B S T R A C T
HTLV-1 is the causal agent of Adult $T$ cell Leukemia/lymphoma (ATLL) and HTLV-1-associated Myelopathy/Tropical Spastic Paraparesis (HAM/TSP). The immune response to HTLV-1-infection is polarized to the Th1-type, and the presence of CXCL9/CXCL10 chemokines may lead to an increase in the recruitment of pro-inflammatory molecules in spinal cord tissue, contributing to the damage observed in the development of HAM/TSP. It has been observed that in chronic helminth-infections, such as schistosomiasis, there is a deviation toward the Th2/regulatory immune response.

Objective: To evaluate the ability of Schistosoma spp. proteins to decrease the in vitro CXCL9 and CXCL10 production by PBMC of HTLV-1-infected individuals.

Methods: The Schistosoma proteins rSm29, rSh-TSP-2 and PIII were added to PBMC cultures of HTLV-1infected individuals and the levels of chemokines in the supernatants were measured using a sandwich ELISA method.

Results: The addition of rSm29 to the cultures resulted in decreased production of CXCL9 in all the analyzed individuals and HAM/TSP group $(18167 \pm 9727 \mathrm{pg} / \mathrm{mL}, \mathrm{p}=0.044 ; 20237 \pm 6023 \mathrm{pg} / \mathrm{mL}, \mathrm{p}=0.028$, respectively) compared to the levels in unstimulated cultures $(19745 \pm 9729 \mathrm{pg} / \mathrm{mL} ; 25078 \pm 2392 \mathrm{pg} / \mathrm{mL}$, respectively). The addition of rSh-TSP-2 decreased the production of CXCL9 in all studied individuals and carriers group $(16136 \pm 9233 \mathrm{pg} / \mathrm{mL}, \mathrm{p}=0.031 ; 13977 \pm 8857 \mathrm{pg} / \mathrm{mL}, \mathrm{p}=0.026)$ vs unstimulated cultures $(19745 \pm 9729 \mathrm{pg} / \mathrm{mL} ; 18121 \pm 10508 \mathrm{pg} / \mathrm{mL}$, respectively). Addition of PIII did not alter the results. There was no significant change in the levels of CXCL10 by the addition of the studied proteins.

Conclusion: The Schistosoma proteins used in this study were able to down modulate the production of CXCL9, a chemokine associated with the inflammatory process in HTLV-1-infection.
\end{abstract}

(c) 2016 Elsevier B.V. All rights reserved.

\section{Introduction}

The human T cell lymphotropic virus type 1 (HTLV-1) is a retrovirus discovered in the late 1970s (Van Dooren et al., 2001). It is the

\footnotetext{
* Corresponding author at: Serviço de Imunologia, Hospital Universitário Professor Edgard Santos, Universidade Federal da Bahia, $5^{\circ}$ andar, Rua João das Botas SN, Canela, 40110-16, Salvador, Bahia, Brazil.

E-mail address: 1lmmll10@gmail.com (L.M. Lima).
}

causal agent of adult T cell leukemia/lymphoma (ATLL) and HTLV1-associated myelopathy/Tropical Spastic Paraparesis (HAM/TSP) (Osame et al., 1986). Other manifestations associated with HTLV1 infection include Sjõgren Syndrome (Eguchi et al., 1992), uveitis (Mochizuki et al., 1992), polymyositis and artropathy (Morgan et al., 1989), erectile dysfunction (Castro et al., 2005), urologic manifestations (Castro et al., 2007) and neurological changes that do not meet the diagnostic criteria of HAM/TSP (Zunt et al., 1999). In individuals infected with HTLV-I but considered asymptomatic, a high prevalence of paraparesis, urinary symptoms, arthralgia, erectile 
dysfunction, gingivitis and periodontitis are identified when compared with seronegative individuals (Caskey et al., 2007).

HAM/TSP is clinically characterized by the insidious onset of spastic paraparesis that is progressive and can eventually lead to wheelchair dependency (Van Dooren et al., 2001; Araújo Ade et al., 1993). About $30 \%$ of patients with HAM/TSP become paraplegic and confined to bed about ten years after the onset of illness (CarneiroProietti et al., 2002). Patients with HAM/TSP have a higher proviral load and higher production of pro-inflammatory cytokines compared to HTLV-1 carriers (Yoshida, 2001; Santos et al., 2004). While HTLV-1 virus induces a Th1-polarized immune response, in chronic Schistosoma mansoni infection the immune response is polarized to the Th2/regulatory type (Pearce and MacDonald, 2002). In a previous study we showed that individuals with HAM/TSP had a lower frequency of infection with helminths (S. stercoralis and/or S. mansoni) when compared to asymptomatic individuals (Porto et al., 2005). These data may suggest that helminth infections can protect HTLV-1 carrier individuals against HAM/TSP development.

In experimental models, it has been shown that infection with $S$. mansoni or injection of their soluble products prevents Th1 inflammatory diseases, such as type I diabetes, psoriasis and colitis (Cooke et al., 1999; Atochina, 2006). Our group has shown that the Schistosoma spp. surface proteins rSm29, rSh-TSP2 and PIII, are able to down-modulate the in vitro production of the inflammatory cytokine IFN- $\gamma$ in HTLV-1-infected individuals. The decrease in IFN$\gamma$ production in this study was coincidental with an increase in levels of the regulatory cytokine IL-10 (Lima et al., 2013).

In addition to the pro-inflammatory cytokines, the chemokines, small proteins involved in normal traffic of leukocytes and recruitment of leukocytes to sites of injury, have been recognized for contributing to the inflammatory response observed in HAM/TSP (Narikawa et al., 2005; Montanheiro et al., 2007). Studies conducted by our group showed that the Chemokine $\mathrm{C}-\mathrm{X}-\mathrm{C}$ motif ligand 9 (CXCL-9) and Chemokine C-X-C motif ligand 10 (CXCL-10), recognized as important in the recruitment of Th1 cells, were increased in the serum of patients with HAM/TSP compared to asymptomatic HTLV-I infected individuals or healthy controls. This suggests that the presence of these molecules may lead to an increase in the recruitment of pro-inflammatory molecules to spinal cord tissue, contributing to the damage observed in the development of HAM/TSP (Guerreiro et al., 2006; Shevach, 2002). Our hypothesis in this study was that Schistosoma proteins induce IL-10 production, which in turn decreases the production of CXCL9 and CXCL10 by PBMC of HTLV-1-infected individuals.

\section{Methodology}

\subsection{Study population}

A total of $30 \mathrm{HTLV}$-1-infected subjects of different clinical forms of HTLV-1-infection from the Multidisciplinary HTLV-1 Clinic of the Immunology Service, Federal University of the Bahia, SalvadorBahia-Brazil were enrolled in this study. The infected individuals as well as the healthy subjects (control group; $n=8$ ) were of both genders and aged between 18-60 years old. They were negative to helminth infections, by parasitological assays using Hoffman sedimentation method and we excluded the of $S$. mansoni previous exposure, by measuring the levels of serum-specific IgE to S. mansoni soluble adult worm antigen (SWAP; Table 1), using ELISA method (Souza-Atta et al., 1999). Because of the potential to interfere with the immune response, we did not include patients who use immunosuppressive drugs, individuals infected with HIV1/HIV2 or with hepatitis B and C. For the same reason, pregnant women were not included in the study.
The study was approved by the Ethics Committee of the Maternidade Climério de Oliveira/Federal University of Bahia, and an informed written consent was obtained from all study participants.

\subsection{Laboratory evaluation}

Anti-HTLV-1 antibody titers were measured using enzymelinked immunosorbent assay (ELISA) technique (Cambridge Biotech Corp, Worcester, MA, USA). Positive sample results were confirmed using Western blot (HTLV Blot 2.4, Genelabs, Science Park Drive, Singapore).

\subsection{Schistosoma spp. antigens}

The antigens used in this study included a $S$. mansoni recombinant protein $\mathrm{Sm} 29$, a membrane-bound glycoprotein located on the tegument of the adult worm and lung stage schistosomula (Cardoso et al., 2006); rSh-TSP-2, a recombinant protein (tetraspanin) from the S. haematobium tegument (Tran et al., 2006); and PIII, which is a fraction of $S$. mansoni soluble adult worm antigen (SWAP) obtained by anion exchange chromatography (Hirsch and Goes, 1996).

The Sm29 and ShTSP-2 recombinant proteins were produced in Escherichia coli and levels of lipopolysaccharide (LPS) contamination tested by a commercially available chromogenic LAL end-point assay kit (Cambrex, Charles City, IA, USA), were below $0.25 \mathrm{ng} / \mathrm{mL}$. In order to neutralize potential effects of LPS found in low levels in the recombinant antigens, Polymyxin B was added to cell cultures every $12 \mathrm{~h}$ according to an established protocol (Cardoso et al., 2007).

\subsection{PBMC cultures and cytokine/chemokine determination}

All patients donated blood for peripheral blood mononuclear cell (PBMC) isolation. PBMCs were obtained by density-gradient centrifugation using lymphocyte separation media (LSM; Organon Teknika, BioMerieux, inc), and PBMCs $\left(3 \times 10^{6}\right.$ cells $\left./ \mathrm{mL}\right)$ were cultured with RPMI 1640 (Gibco, Grand Island, NY, USA) plus 10\% heat inactivated human AB Rh+ serum (Sigma Chemical Co., St. Louis, $\mathrm{MO})$, antibiotics and glutamine. The cultures were performed in the presence or absence of $\mathrm{rSm} 29(5 \mu \mathrm{g} / \mathrm{mL}), \mathrm{rShTSP}-2(5 \mu \mathrm{g} / \mathrm{mL})$ and PIII $(10 \mu \mathrm{g} / \mathrm{mL})$ and were incubated at $37^{\circ} \mathrm{C}$ in $5 \% \mathrm{CO}_{2}$ atmosphere in 24 well plates for $72 \mathrm{~h}$. Supernatants were collected for cytokine and chemokine measurements.

Levels of CXCL9, CXCL10 and IL-10 were measured in the supernatants by sandwich ELISA using commercially available kits (OptEIA; BD Bioscience, San Jose,CA,USA). The results were expressed as picograms per milliliter $(\mathrm{pg} / \mathrm{mL})$, on the basis of a standard curve.

\subsection{Statistical analysis}

A nonparametric Wilcoxon Signed-Rank Test for matched pairs was used to analyze the effect of the addition of Schistosoma proteins on the production of CXCL9 and CXCL10. The Fisher exact test was used to compare proportions. The Spearman $r$ test was used to analyze correlations. An alpha $(\alpha)$ error of $5 \%(p<0.05)$ was considered as statistically significant. SPSS 9.0 software (IBM software, New York, USA) was used for statistical analysis. Statistical analysis and graphical representation were performed using Graphpad PRISM 5.0 software (La jolla, CA, USA).

\section{Results}

The demographic features of the studied population are shown in Table 1 . The median age (minimum-maximum) of the studied subjects and healthy controls were 50 (23-60) and 28 (24-31) years 
Table 1

Demographic characteristics of individuals enrolled in the study.

\begin{tabular}{|c|c|c|c|c|c|}
\hline HTLV-1+ Individuals & $\begin{array}{l}\text { Carriers } n=23 \\
(77 \%)\end{array}$ & $\begin{array}{l}\text { HAM/TSP n =7 } \\
(23 \%)\end{array}$ & $\begin{array}{l}\text { Total } n=30 \\
(100 \%)\end{array}$ & $\begin{array}{l}\text { Healthy } \\
\text { Controls } n=8\end{array}$ & p value ${ }^{*}$ \\
\hline Age years; median (min-max) & $\begin{array}{l}49 \\
(23-60)\end{array}$ & $\begin{array}{l}51 \\
(46-53)\end{array}$ & $\begin{array}{l}50 \\
(23-60)\end{array}$ & $\begin{array}{l}28 \\
(24-31)\end{array}$ & $>0.05$ \\
\hline Gender (\% of male) M:F & $\begin{array}{l}22 \\
5: 18\end{array}$ & $\begin{array}{l}57 \\
4: 3\end{array}$ & $\begin{array}{l}30 \\
9: 21\end{array}$ & $\begin{array}{l}6 \\
6: 8\end{array}$ & $<0.05$ \\
\hline Viral charge (Copies $/ 10^{6}$ cels; mean \pm Median) & $103148,8 \pm 39166,67$ & $227801 \pm 157729$ & $\begin{array}{l}138105,4 \pm 42838 \\
9\end{array}$ & - & $>0.05$ \\
\hline SWAP-specific IgE (mean \pm SD) & $0.16 \pm 0.06$ & $0.21 \pm 0.07$ & $0.19 \pm 0.06$ & $0.27 \pm 0.06$ & $>0.05$ \\
\hline
\end{tabular}

* Carriers vs HAM/TSP; Cutoff IgE: 0.36.

old, respectively. There was no significant difference in the age between the group of carriers (median $=49 ; 23-60$ year old) and those with HAM/TSP (median $=51 ; 43-53$ years old; $p>0.05$ ). In the group of patients with HAM/TSP and in control group there was a higher prevalence of males ( $57 \%$ and $75 \%$, respectively) compared to the carriers (22\%; $\mathrm{p}<0.05$; Table 1$)$.

The levels of CXCL9 and CXCL10 in the supernatants of PBMC cultures in HTLV-1 infected individuals is show in Fig. 1 and Fig. 2. The mean level of CXCL9 in unstimulated cultures in HTLV-1-infected individuals was $19745 \pm 9729 \mathrm{pg} / \mathrm{mL}$ and in the control individuals was $10350 \pm 3793$ (Fig. 1A and D). A slightly reduction in the production of CXCL9 was observed in the supernatant of PBMC cultures when $\mathrm{rSm} 29$ was added to the cultures of infected individuals and healthy controls $(18167 \pm 9727 \mathrm{pg} / \mathrm{mL}$ and $1135 \pm 961 \mathrm{pg} / \mathrm{mL}$, respectively), compared to the culture of unstimulated cells ( $p=0.044$ and $p=0.012$ respectively; Fig. $1 \mathrm{~A}$ and D). The addition of rShTSP-2 also resulted in a decrease in the mean level of CXCL9 in cell cultures of infected $(16136 \pm 9233 \mathrm{pg} / \mathrm{mL})$ and healthy controls $(661 \pm 719 \mathrm{pg} / \mathrm{mL})$, compared to the unstimulated cells $(\mathrm{p}=0.031$ and $\mathrm{p}=0.012$ respectively). The addition of PIII did not alter the production of this chemokine in HTLV-1 individuals $(19298 \pm 10048 \mathrm{pg} / \mathrm{mL}, \mathrm{p}>0.05)$, however there was an increase in the levels of this chemokine in cell cultures of control individuals
$(4392 \pm 5390 \mathrm{pg} / \mathrm{mL}, \mathrm{p}=0.012)$. In the group of carrier individuals (Fig. 1B), the addition of rShTSP-2 resulted in decreased production of CXCL9 $(13977 \pm 8857 \mathrm{pg} / \mathrm{mL}$ ) compared to the unstimulated cells $(18121 \pm 10508 \mathrm{pg} / \mathrm{mL} ; \mathrm{p}=0.026)$. However, the addition of $\mathrm{rSm} 29$ and PIII did not alter significantly the mean level of this chemokine $(17537 \pm 10520 \mathrm{pg} / \mathrm{mL} ; 18177 \pm 10926 \mathrm{pg} / \mathrm{mL}$, respectively $)$.

In the group of HAM/TSP subjects, the mean level of CXCL9 in unstimulated cultures was $25078 \pm 2392 \mathrm{pg} / \mathrm{mL}$. The addition of rSm29 to the cultures decreased the levels of CXCL9 to $20237 \pm 6023 \mathrm{pg} / \mathrm{mL}(\mathrm{p}=0.028$; Fig. 1C). The addition of rShTSP-2 and PIII antigens did not alter significantly the production of this chemokine, $(23230 \pm 6477 \mathrm{pg} / \mathrm{mL}$ and $22982 \pm 4771 \mathrm{pg} / \mathrm{mL}$, respectively) compared to the mean level of unstimulated cultures.

Regarding the production of CXCL10, there was no significant difference in the mean levels of this chemokine after treatment of PBMCs with Schistosoma proteins in HTLV-1-infected individuals (Fig. 2). However, the level of this chemokine in unstimulated PBMC cultures from healthy individuals $(2704 \pm 374 \mathrm{pg} / \mathrm{mL})$ reduced after $\mathrm{rSm} 29(430 \pm 240 \mathrm{pg} / \mathrm{mL} ; \mathrm{p}=0.012) \mathrm{rShTSP}-2(376 \pm 262 \mathrm{pg} / \mathrm{mL}$; $\mathrm{p}=0.012)$ and PIII $(1151 \pm 1038 \mathrm{pg} / \mathrm{mL} ; \mathrm{p}=0.017)$ stimulation. We also measured IL-10 production in the supernatant of PBMC cultures and correlated the mean levels of this cytokine with the levels of CXCL9 and CXCL10 in 18 individuals of the HTLV-1-carrier group

\section{Total of individuals}

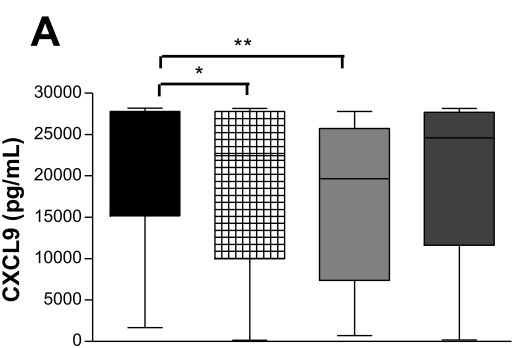

HAMTSP

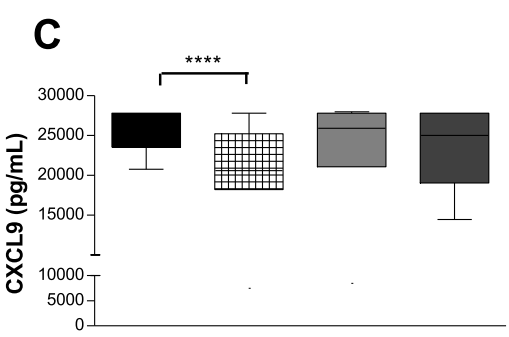

\section{Carriers}
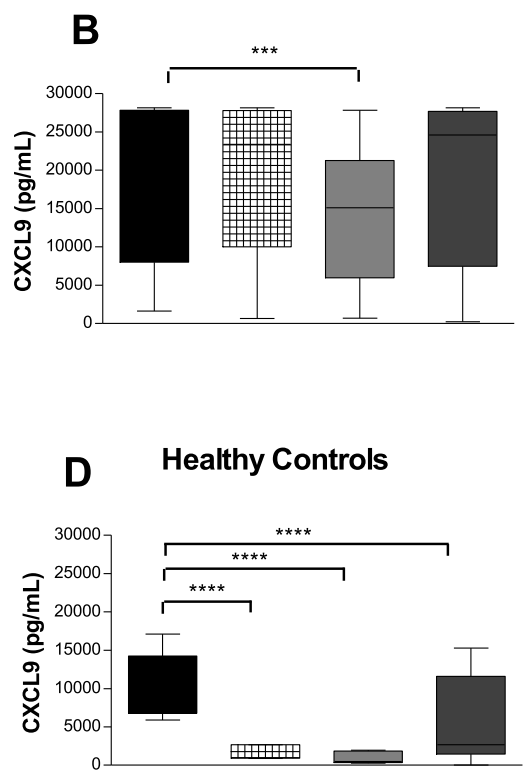

rShTSP-2

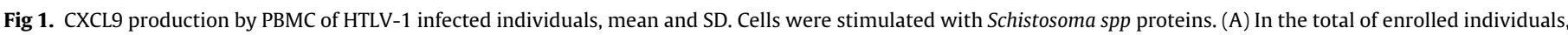
(B) in the carriers of the virus $(n=23),(C)$ in the HAM/TSP group $(n=7)$ and $(D)$ in the controls group $(n=8) .{ }^{*} p=0.04 ;{ }^{* *} p=0.031 ;{ }^{* * *} p=0.026 ;{ }^{* * * *} \mathrm{p}=0.028,{ }^{* * * * *} \mathrm{p}=0.012$. 

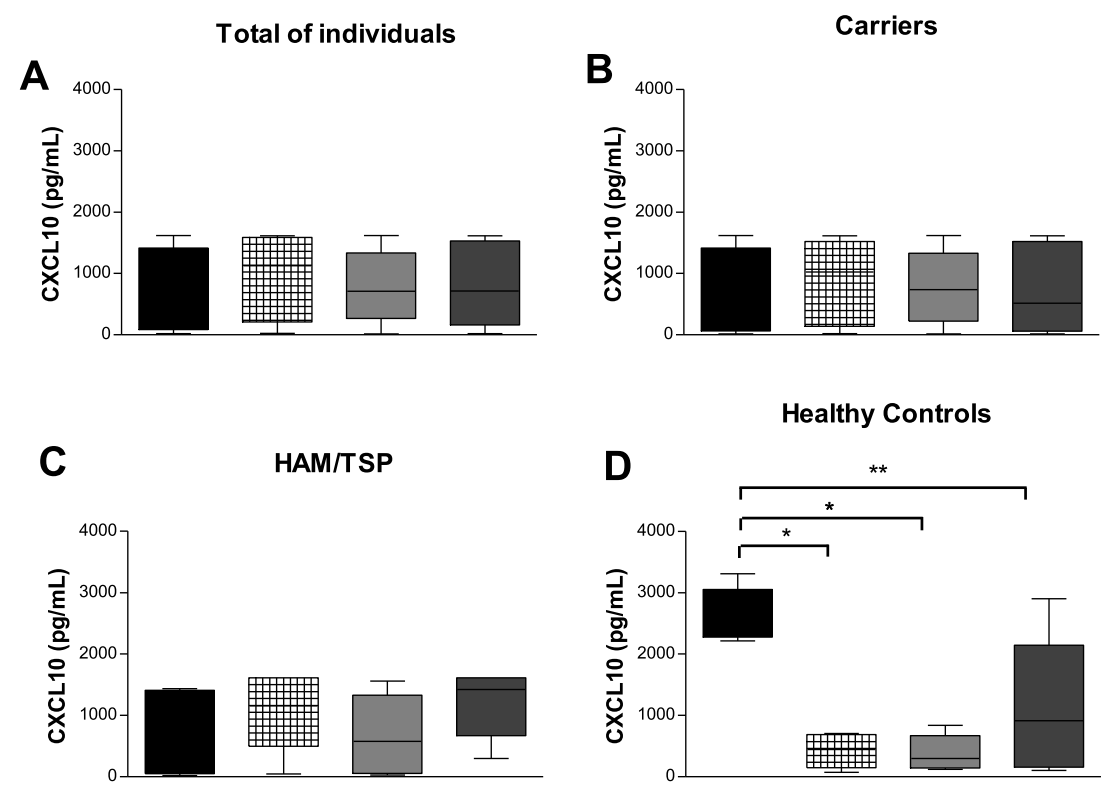

without antigens $\mathbb{\# S m} 29$

rShTSP-2

PIII

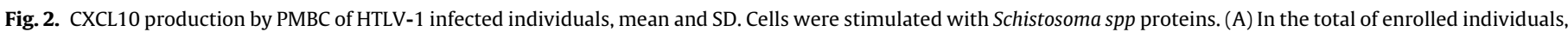
(B) in the carriers of the virus $(n=23),(C)$ in the HAM/TSP group $(n=7)$ and (D) in the controls group $(n=8) . p^{*}=0.012,{ }^{* *} p=0.017$.

(Fig. 3). There was no significant correlation between IL-10 and CXCL9 in unstimulated cultures in the carriers group $(r=-0.15$; Fig. 3A). There was, however a positive correlation between IL10/CXCL9 when PBMCs of carriers individuals were stimulated with $\mathrm{rSm} 29(\mathrm{r}=0.54, \mathrm{p}=0.02$; Fig. $3 \mathrm{~B})$. There was also a positive correlation between these two molecules in the carriers group when PBMCs were stimulated with rSh-TSP-2 $(r=0.70, p=0.0019$; Fig. 3C) and with PIII ( $r=0.68, p=0.0026$; Fig. 3D).

In the HAM/TSP group no significant correlation was observed between levels of IL-10 and CXCL9 in unstimulated cultures

\section{Carriers}

A Without antigens
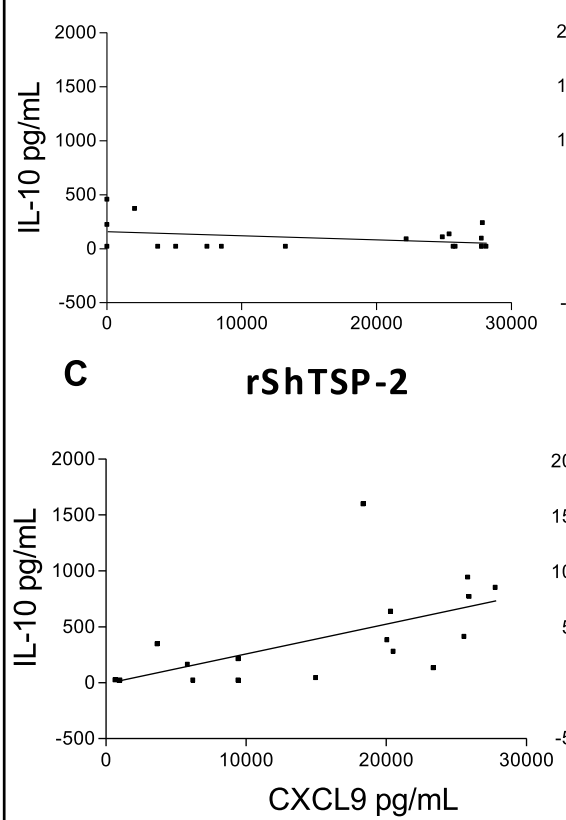

B $\quad$ rSm 29

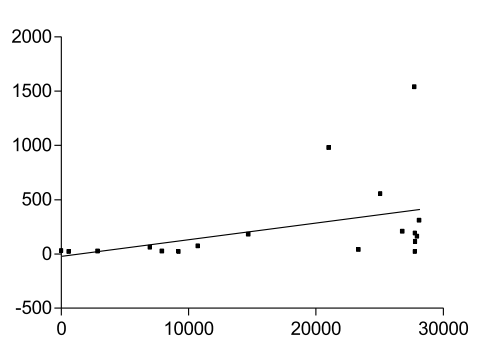

D

P III

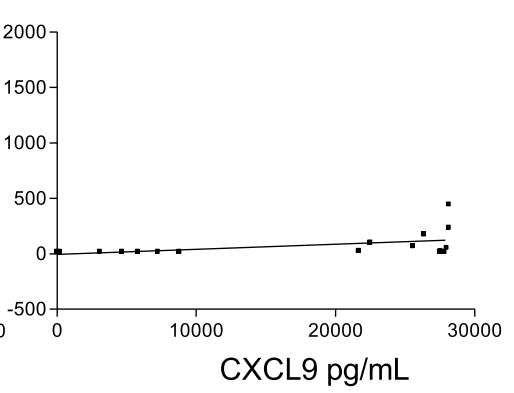

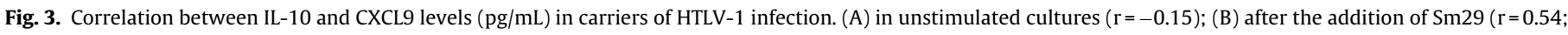
$\mathrm{p}=0.02)$; $(\mathrm{C})$ after the addition of Sh-TSP-2 ( $\mathrm{r}=0.70 ; \mathrm{p}=0.0019)$, and (D) after the addition of PIII $(\mathrm{r}=0.68 ; \mathrm{p}=0.0026)$. Spearman Correlation. 
$(\mathrm{r}=-0.68)$ and in cultures stimulated with $\mathrm{rSm} 29(\mathrm{r}=-0.39), \mathrm{rSh}-$ TSP-2 $(r=-0.26)$ and PIII $(r=-0.40, p>0.05$; not shown $)$.

There was also no significant correlation between levels of IL-10 and CXCL10 in the carriers and HAM/TSP groups in unstimulated cultures $(\mathrm{r}=-0.013, \mathrm{r}=-0.67$, respectively) and in cultures stimulated with $\mathrm{rSm} 29(\mathrm{r}=-0.012, \mathrm{r}=0.36$, respectively), rSh-TSP$2(r=-0.31, r=0.29$, respectively) and PIII $(r=0.0038, r=0.018$, respectively; not shown).

We also performed correlations between CXCL9 with viral titres and there was no significant correlation among viral burden and levels of CXCL9 in the total of individuals enrolled in the study in unstimulated cultures $(\mathrm{r}=0.6282)$, in cultures stimulated with rSm29 $(r=-0,1363)$, stimulated with rSh-TSP-2 $(r=0,4299)$ and with PIII $(0,4018 ; \mathrm{p}<0.05)$. There was also no significant correlation between CXCL9 and viral titres when we considered the carriers and HAM/TSP groups $(r=-0,08945$ and $r=0,6126$ in the unstimulated cultures; $r=-0,2826$ and 0,5714 in cultures stimulated with rSm29; $r=-2592$ and $r=0,1482$ in cultures stimulated with rShTSP-2 and $r=-0,2442$ and $r=0,2342$ in response to PIII antigen, respectively).

The correlation between levels of CXCL10 and viral burden also did not differs in the total of analyzed individuals in unstimulated cultures $(r=0.05117)$, in cultures stimulated with $r S m 29(r=0.1733)$, rSh-TSP-2 $(r=0.2516)$ and with PIII $(r=0.3361$, $p>0.05$ ). No significant difference was also documented in the carriers and HAM/TSP groups in unstimulated cultures $(r=-0.1498$ and $r=0.6429$, respectively), in cultures stimulated with $\mathrm{rSm} 29$ $(r=-0.1198$ and $r=0.3214$, respectively), stimulated with $r S h-T S P-$ $2(r=0.08776$ and $r=0.5357)$ and with PIII $(r=0.3118$ and $r=0.2703$, respectively).

\section{Discussion}

Studies have shown that HTLV-1-infected individuals produce higher levels of IFN- $\gamma$ and TNF when compared to donor blood negative for HTLV-1 (Santos et al., 2004; Carvalho et al., 2001), and that exaggerated Th1 immune response participates in the pathogenesis of HAM/TSP (Nagai and Jacobson, 2001; Lima et al., 2005; Ohbo et al., 1991; Andrada-Serpa et al., 1996; Nishimoto et al., 1990; Santos et al., 2004).

We previously showed that the Schistosoma proteins rSm29, rSh-TSP-2 and PIII are able to reduce the levels of IFN- $\gamma$ in HTLV1 infected individuals (Lima et al., 2013). In addition to cytokines, chemokines also participate in the inflammatory process associated with HTLV-1 infection (Narikawa et al., 2005; Montanheiro et al., 2007). It has been shown that the chemokines CXCL9 and CXCL10 are increased in serum of patients with HAM/TSP compared with asymptomatic HTLV-I individuals or healthy controls (Guerreiro et al., 2006). These molecules may lead to an increase in the recruitment of pro-inflammatory molecules into the medullar tissue, contributing to the damage associated with the development of HAM/TSP (Guerreiro et al., 2006; Shevach, 2002). These biomarkers may provide a means for early identification of patients at increased risk of disease progression (Sato et al., 2013).

In this study we showed that the addition of the Schistosoma proteins $\mathrm{rSm} 29$ and rSh-TSP-2 to cultured cells resulted in reduced levels of CXCL9 in supernatants of PBMCs compared to unstimulated cells of individuals with HTLV-1, in all individuals. The rSh-TSP-2 antigen reduced the levels of CXCL9 in PBMC cultures compared to unstimulated cells in carriers individual. Also, in the HAM/TSP group the addition of $\mathrm{rSm} 29$ antigen resulted in reduced levels of CXCL9 in comparison to the levels of this chemokines in unstimulated cultures.

Levels of CXCL10 were not affected by the presence of Schistosoma proteins in this study. It was able, however to reduction the levels of this chemokine in healthy controls. Failure to reduce the production of CXCL10, however, does not rule out the possibility that production of this chemokine in vivo is diminished by these Schistosoma proteins, since CXCL9 and CXCL10 are strongly induced by IFN- $\gamma$ (Müller et al., 2010). It has been previously shown that these proteins are able to reduce IFN- $\gamma$ production (Lima et al., 2013), and the decrease in IFN- $\gamma$ levels could lead to the further reduction of CXCL9 and CXCL10 production in vivo.

In in vitro studies using humans mononuclear cells, authors have shown that a polysaccharide of Cryptococus neoformans is able to affect the cell response to IFN- $\gamma$ by inhibiting the production of CXCL10 (Nogueira, 2012). Also, infection of human neutrophil with Anaplasma pagocytophilum impairs IFN-gamma signaling and the secretion of the IFN-gamma-inducible chemokines CXCL10 and CXCL9 was markedly inhibited in infected neutrophils. (Bussmeyer et al., 2010). About the role of IL-10, in rat peritonitis model, Kupffer cells depletion and neutralization of IL-10 resulted in increased expression of chemokines and the numbers of inflammatory infiltrate cells in the lung, leading to exacerbated acute lung injury and sepsis (Kono et al., 2008).

The main goal in this study was to determine the ability of Schistosoma antigens in down modulating the production of CXCL9 and CXCL10 by PBMC of HTLV-1-infected individuals. it was observed lower levels of these chemokines in serum from healthy controls when compared to HTLV-1-infected individuals.

Since previous studies of our group showed that the Schistosoma spp proteins used in this study are capable of negatively regulating Th1-type immune responses in vitro in HTLV-1-infected individuals (Lima et al., 2013), the decreased levels of CXCL-9 observed in this study may reduce the risk of damage associated with the neurological changes that meet the criteria of HAM/TSP. However, further studies are necessaries to evaluate if the changes observed in immunological parameters are indeed related to changes in the clinical outcome.

It has also been shown that rSm29, rSh-TSP-2 and PII are able to increase IL-10 production by PBMCs from HTLV-1-infected individuals (Lima et al., 2013). IL-10 is an important immunomodulatory cytokine and plays an important role in maintaining the carrier status in HTLV-1 infected individuals, balancing the production of IFN- $\gamma$ (Britto-Melo et al., 2007). The previously demonstrated low ratio of IFN- $\gamma /$ IL-10 for some Schistosoma spp proteins support the hypothesis that these molecules can be used to prevent diseases in HTLV-1 infection (Lima et al., 2013). Indeed, although IL-10 was assessed only in individuals of the carrier group, we showed a positive correlation between IL-10 and CXCL9 after the addition of Schistosoma spp proteins in cultures. Our data prompt us to speculate that IL-10 may be produced in an attempt to control the high production of inflammatory molecules such as CXCL9.

Taken together, our results show that the Schistosoma proteins rSm29 and rSh-TSP-2 used in this study were able to reduce the in vitro production of the chemokine CXCL9, an inflammatory marker in HTLV-1 infection. This modulation was unlikely to be dependent upon IL-10, since there was a positive correlation between this cytokine and CXCL9 in the carrier group. Other studies are necessary to further clarify the mechanisms underlying the downmodulation of chemokine production by Schistosoma spp. proteins.

\section{Funding}

$$
\text { CNPQ (Universal 479417/2008 3), NIH (R01AI079238A). }
$$

\section{Acknowledgements}

We thank Edgar M. Carvalho for the support in the development of this work, Maria de La Gloria Orge Orge who assisted us in 
the recruitment of patients, Bas S. Wind for the support in English language, and the patients who participated in this study.

\section{References}

Andrada-Serpa, M.J., Schor, D., Araujo, A.Q., Rumjanek, V.M., 1996. Immunological features of HTLV-I myelopathy in Rio de Janeiro, Brazil, and in vitro effects of cyclosporin A. J. Neurol. Sci. 139, 7-14.

Araújo Ade, Q., Alfonso, C.R., Schor, D., Leite, A.C., de Andrada-Serpa, M.J., 1993. Clinical and demographic features of HTLV-1 associated myelopathy/tropical spastic paraparesis (HAM/TSP) in Rio de Janeiro, Brazil. Acta. Neurol. Scand. 88 (1), 59-62.

Atochina, O.H.D., 2006. Prevention of psoriasis-like lesions development in fsn/fsn mice by helminth glycans. Exp. Dermatol. 158, 461-468.

Britto-Melo, G.E., Peruhype-Magalhães, V., Teixeira-Carvalho, A., Barbosa-Stancioli, E.F., Carneiro-Proietti, A.B., Catalan-Soares, B., 2007. IL-10 produced by CD4+ and CD8+ T cell emerge as a putative immunoregulatory mechanism to counter-balance the monocyte-derived TNF-alpha and guarantee asymptomatic clinical satatus durin chronic HTLV-1 infection. Clin. Exp. Immunol. 147, 35-44.

Bussmeyer, U., Sarkar, A., Broszat, K., Ludemann, T.Y., Oller, S., van Zandbergen, T., Bogdan, C., Behnen, M., Dumler, J.S., san Loewenich, F.D., Solbach, W., Laskay, T., 2010. Impairment of gamma interferon signaling in human neutrophils infected with Anaplasma phagocytophilum. Infect. Immun. 1, 358-363.

Cardoso, F.C., Pacifico, R.N., Mortara, R.A., Oliveira, S.C., 2006. Human antibody responses of patients living in endemic areas for Schistosomiasis to the Tegumental protein Sm29 identified through genomic studies. Clin. Exp. Immunol. 144, 382-391.

Cardoso, L.S., Araujo, M.I., Goes, A.M., Pacifico, L.G., Oliveira, R.R., Oliveira, S.C., 2007. Polymyxin b as inhibitor of lps contamination of Schistosoma mansoni recombinant proteins in human cytokine analysis. Microb. Cell. Fact. 6, 1.

Carneiro-Proietti, A.B., Ribas, J.G., Catalan-Soares, B.C., Martins, M.L., Brito-Melo, G.E., Martins-Filho, O.A., Pinheiro, S.R., Araújo Ade, Q., Galvão-Castro, B., de Oliveira, M.S., Guedes, A.C., Proietti, F.A., 2002. Infection and disease caused by the human T cell lymphotropic viruses type I and II in Brazil. Rev. Soc. Bras. Med. Trop. 35, 499-508.

Carvalho, E.M., Bacellar, O., Porto, A.F., Braga, S., Galvao-Castro, B., Neva, F., 2001. Cytokine profile and immunomodulation in asymptomatic human Tlymphotropic virus type 1-infected blood donors. J. Acquir. Immune. Defic. Syndr. 27, 1-6.

Caskey, M.F., Morgan, D.J., Porto, A.F., Giozza, S.P., Muniz, A.L., Orge, G.O., Travassos, M.J., Barron, Y., Carvalho, E.M., Glesby, M.J., 2007. Clinical manifestations associated with HTLV type I infection: a cross-sectional study. AIDS Res. Hum. Retroviruses 23, 365-371.

Castro, N., Oliveira, P., Freitas, D., Rodrigues, W., Muniz, A., Carvalho, E., 2005. Erectile dysfunction and HTLV-1 infection: a silent problem. Int. J. Impot. Res. 17, 364-369.

Castro, N.M., Rodrigues W.Jr. Freitas, D.M., Muniz, A., Oliveira, P., Carvalho, E.M., 2007. Urinary symptoms associated with human T-cell lymphotropic virus type I infection: evidence of urinary manifestations in large group of HTLV-I carriers. Urology 69, 813-818.

Cooke, A., Tonks, P., Jones, F.M., O’Shea, H., Hutchings, P., Fulford, A.J., Dunne, D.W., 1999. Infection with Schistosoma mansoni prevents insulin dependent diabetis mellitus in non-obese diabetic mice. Parasite Immunol. 21, 169-176.

Eguchi, K., Matsuoka, N., Ida, H., Nakashima, M., Sakai, M., Sakito, S., Kawakami, A., Terada, K., Shimada, H., Kawabe, Y., 1992. Primary Sjogren's syndrome with antibodies to HTLV-I: clinical and laboratory features. Ann. Rheum. Dis. 51, 769-776.

Guerreiro, J.B., Santos, S.B., Morgan, D.J., Porto, A.F., Muniz, A.L., Ho, J.L., Teixeira A.L.Jr. Teixeira, M.M., Carvalho, E.M., 2006. Levels of serum chemokines discriminate clinical myelopathy associated with human T lymphotropic virus type 1 (HTLV-I)/tropical spastic paraparesis (HAM/TSP) disease from HTLV-I carrier state. Clin. Exp. Immunol. 145, 296-301.

Hirsch, C., Goes, A.M., 1996. Characterization of fractionated Schistosoma mansoni soluble adult worm antigens that elicit human cell proliferation and granuloma formation in vitro. Parasitology 112, 529-535.

Kono, H., Fujii, H., Tsuchiyna, M., Hirai, Y., Ishii, K., Hosomura, N., Tanaka, N., 2008. Inhibition of the Kupffer cell and neutralization of IL-10 increase the expression of chemokines in the lung in a rat peritonitis model. J. Surg. Res. 150 (2), 169-182.
Lima, M.A., Bica, R.B., Araujo, A.Q., 2005. Gender influence on the progression of HTLV-I associated myelopathy/tropical spastic paraparesis. J. Neurol. Neurosurg. Psychiatry 76, 294-296.

Lima, L.M., Santos, S.B., Oliveira, R.R., Cardoso, L.S., Oliveira, S.C., Góes, A.M., Loukas, A., Carvalho, E.M., Araújo, M.I., 2013. Schistosoma antigens downmodulate the in vitro inflammatory response in individuals infected with Human T cells lymphotropic virus type 1. Neuroimmunomodulation 20, 233-238.

Müller, M., Carter, S., Hofer, M.J., Campbell, I.L., 2010. Review: the chemokine receptor CXCR3 and its ligands CXCL9, CXCL10 and CXCL11 in neuroimmunity-a tale of conflict and conundrum. Neuropathol. Appl. Neurobiol. 36, 368-387.

Mochizuki, M., Yamaguchi, K., Takatsuki, K., Watanabe, T., Mori, S., Tajima, K., 1992. HTLV-I and uveitis. Lancet 339, 1110.

Montanheiro, P., Vergara, M.P., da Silva, Smid J., Duarte, A.J., de Oliveira, A.C. Casseb, J., 2007. High production of RANTES and MIP-1alpha in the tropical spastic paraparesis/HTLV-I-associated myelopathy (TSP/HAM). J. Neuroimmunol. 188, 138-142.

Morgan, O.S., Rodgers-Johnson, P., Mora, C., Char, G., 1989. HTLV-I and polymyositis in Jamaica. Lancet 2, 1184-1187.

Nagai, M., Jacobson, S., 2001. Immunopathogenesis of human T cell lymphotropic virus type I-associated myelopathy. Curr. Opin. Neurol. 14, 381-386.

Narikawa, K., Fujihara, K., Misu, T., Feng, J., Fujimori, J., Nakashima, I., Miyazawa, I., Saito, H., Sato, S., Itoyama, Y., 2005. CSF-chemokines in HTLVI-associated myelopathy: CXCL10 up-regulation and therapeutic effect of interferon-alpha. J. Neuroimmunol. 159, 177-182.

Nishimoto, N., Yoshizaki, K., Eiraku, N., Machigashira, K., Tagoh, H., Ogata, A., Kuritani, T., Osame, M., Kishimoto, T., 1990. Elevated levels of interleukin-6 in serum and cerebrospinal fluid of HTLV-I-associated myelopathy/tropical spastic paraparesis. J. Neurol. Sci. 97, 183-193.

Nogueira, M.R., 2012. Efeito do glucuronoxilomanana (GXM) obtida do Cryptococus neoformans e do Cryptococus gattii sobre a resposta de celulas mononucleares humanas ao IFN- $\gamma$.Dissertação de Mestrado. Universidade Federal do Triângulo Mineiro, Uberaba, MG, pp. 104.

Ohbo, K., Sugamura, K., Sekizawa, T., Kogure, K., 1991. Interleukin-6 in cerebrospinal fluid of HTLV-I-associated myelopathy. Neurology 41, 594-595.

Osame, M., Usuku, K., Izumo, S., Ijichi, N., Amitani, H., Igata, A., Matsumoto, M., Tara, M., 1986. HTLV-1 associated myelopathy, a new clinical entity. Lancet 1, $1031-1032$.

Pearce, E.J., MacDonald, A.S., 2002. The immunobiology of schistosomiasis. Nat. Rev. Immunol. 7, 499-511.

Porto, A.F., Santos, S.B., Muniz, A.L., Basílio V.Jr.W.R. Neva, F.A., Dutra, W.O., Gollob, K.J., Jacobson, S., Carvalho, E.M., 2005. Helminthic infection dow-Regulates type 1 immune responses in human t cell lymphotropic virus type 1 (HTLV-1) carriers and is more prevalet in HTLV-1 carriers than in patients with HTLV-1-associated myelopathy/tropical spastic paraparesis. J. Infect. Dis. 191, 612-618.

Santos, S.B., Porto, A.F., Muniz, A.L., de Jesus, A.R., Magalhães, E., Melo, A., Dutra, W.O., Gollob, K.J., Carvalho, E.M., 2004. Exacerbated inflammatory cellular Immune response characteristics of HAM/TSP is observed in a large proportion of HTLV-1 asymptomatic carriers. BMC Infect. Dis. 4, 7.

Sato, T., Coler-Reilly, A., Utsonomiya, A., Araya, N., Yagishita, N., Ando, H., Yanouchi, J., Inoue, E., Ueno, T., Hosegawa, Y., Nishioka, K., Nakajima, T., Jacobson, S., Izumo, S., Yamano, Y., 2013. CSF, CXCL10, CXCL9, and neopterin as candidate prognostic biomarkers for HTLV-1-associated myelopathy/tropical spastic paraparesis. PLOS Negl. Trop. Dis. 7, 2479.

Shevach, E.M., 2002. CD4+CD25+ suppressor T cells: more questions than answers. Nat. Rev. Immunol. 2, 389-400.

Souza-Atta, M.L., Araujo, M.I., D’Oliveira Junior, A., et al., 1999. Detection of specific IgE antibodies in parasite diseases. Braz. J. Med. Biol. Res. 32, 1101-1105.

Tran, M.H., Pearson, M.S., Bethony, J.M., Smyth, D.J., Jones, M.K., Duke, M., Don, T.A., McManus, D.P., Correa-Oliveira, R., Loukas, A., 2006. Tetraspanins on the surface of Schistosoma mansoni are protective antigens against schistosomiasis. Nat. Med. 7, 835-840.

Van Dooren, S., Selemi, M., Vandamme, A.M., 2001. Dating the origin of the African human T-Cell lymphotropic virus type-1 (HTLV-1) subtypes. Mol. Biol. Evol. 18, 661-671.

Yoshida, M., 2001. Multiple viral strategies of HTLV-1 for dysregulation of cell growth control. Annu. Rev. Immunol. 19, 475-496.

Zunt, J.R., Alarcon, J.O., Montano, S., Longstreth Jr., W.T., Price, R., Holmes, K.K., 1999. Quantitative assessment of subclinical spasticity in human T-cell lymphotropic virus type I infection. Neurology 53, 386-390. 